\title{
EXPERIENCE IN THE TREATMENT OF CONGENITAL SYNDACTYLY IN THE TVER REGIONAL CHILDREN'S HOSPITAL
}

\section{V.M. Krestyashin, L.V. Rasskazov, Yu.N. Ivanov, N.S. Marasanov, V.V. Murga}

\section{Tver State Medical University, Tver, Russia}

Pirogov Russian National Research Medical University, Moscow, Russia Children's Regional Clinical Hospital, Tver, Russia

Syndactyly is a congenital malformation, consisting in the fusion of two or more fingers, accompanied by a cosmetic defect and dysfunction of the limb. According to various authors, syndactyly accounts for more than $50 \%$ of all congenital anomalies of the hand. The frequency of occurrence is 1: 2000-1: 4000. Treatment of congenital syndactyly is most effective in the first two years of life $[1,2]$.

Syndactyly is classified according to the degree of fusion to total and subtotal (Fig. 1,2); by type of adhesion on soft tissue and bone forms; as the affected fingers are simple and complex. Depending on this, one or another method of correction of this defect can be chosen.
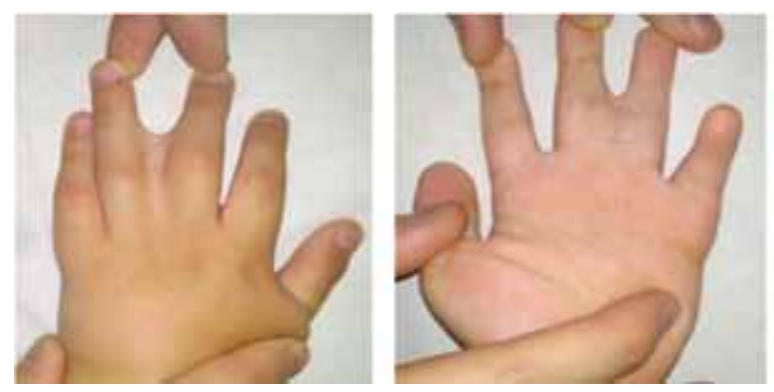

Fig. 1. Simple subtotal form of syndactyly
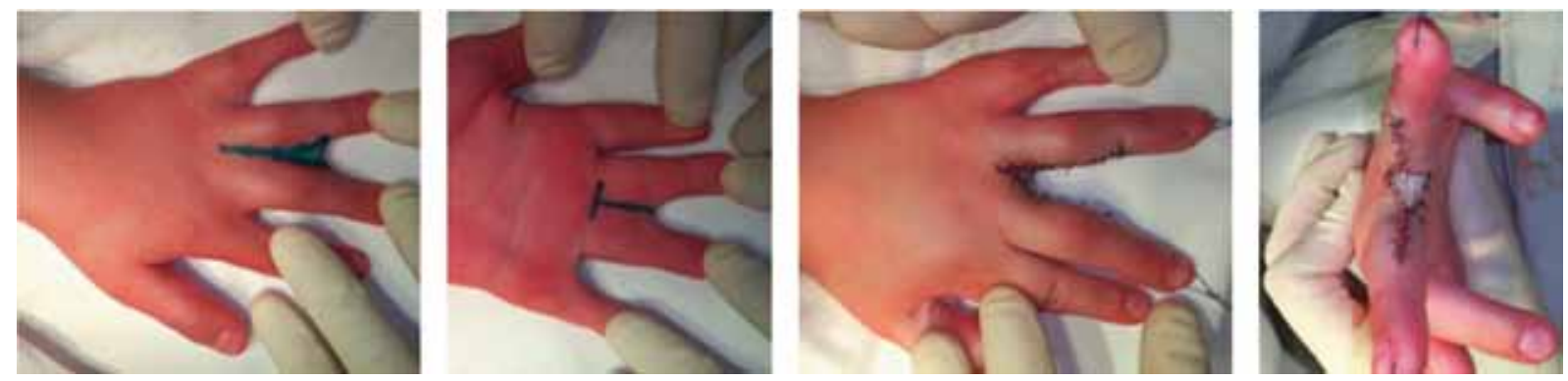

Fig. 3.Using V-Y flap for release of subtotal congenital syndactyly 

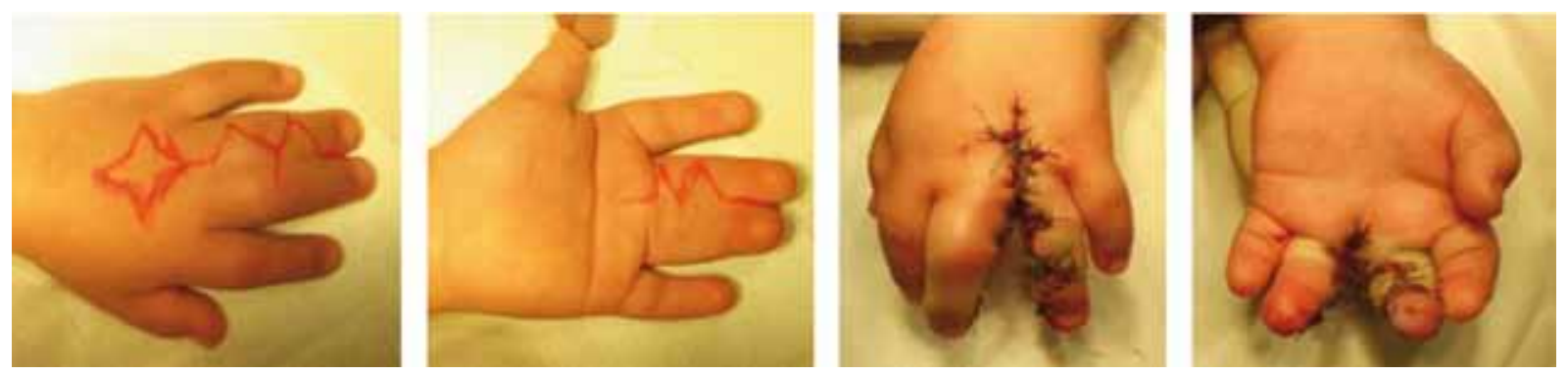

Fig. 4. Using dorsal plane-shaped advancement flap for the reconstruction of web space
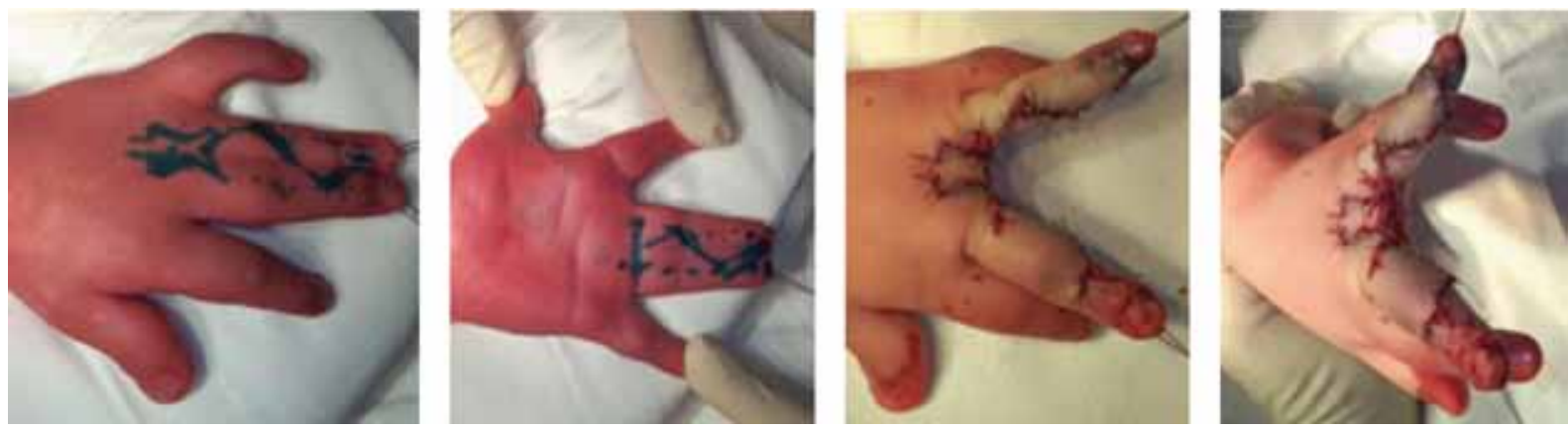

Fig. 5. Using hourglass dorsal advancement flapfor the reconstruction of web space
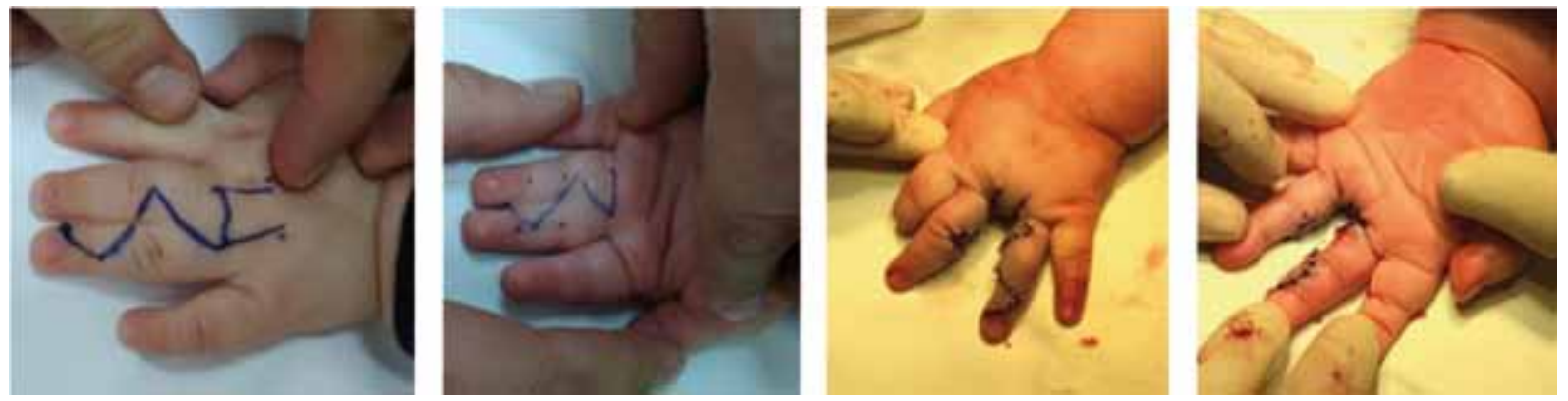

Fig. 6. Using squaredorsaladvancement flapfor the reconstruction of web space

\section{CONCLUSION}

Syndactyly is a complex defect of the hand, which requires a differentiated approach in the choice of surgical correction methods. The most effective are operations that allow the formation of web spaces without using skin grafts. Given this, the task of the orthopedic surgeon is to select the optimal technique that will be the least traumatic and more cosmetically beneficial.

\section{REFERENCES}

1. Kempton, S. J., Michelotti, B. F., Salyapongse, A. N., \&Bentz, M. L. (2019). Syndactyly Reconstruction. Global Reconstructive Surgery, 307-311.

2. Samson, P., \&Salazard, B. (2008). Syndactylies. Chirurgie de La Main, 27, S100-S114.
3. Yamashita, K., Yotsuyanagi, T., YamaUCHI, M., Sugai, A., Gonda, A., Kato, S., \& Kita, A. (2016). Subcutaneous pedicle V-Y flap for release of incomplete congenital syndactyly. Journalof Plastic, Re constructive\&AestheticSurgery, 69(8), e186-e191.

4. Liu, J., Zheng, H., Chen, Z., Dai, X., SChillING, A. F., \&MACHENS, H.-G. (2015). Dorsal plane-shaped advancement flap for the reconstruction of web space in syndactyly without skin grafting: A preliminary report. Journal of Plastic, Reconstructive \& Aesthetic Surgery, 68(11), e167-e173.

5. Ni, F., MaO, H., Yang, X., Zhou, S., Jiang, Y., \& WANG, B. (2015). The Use of an Hourglass Dorsal Advancement Flap Without Skin Graft for Congenital Syndactyly. The Journal of Hand Surgery, 40(9), 1748-1754.e1. 